\title{
Phylogenetic relationships of the neon tetras Paracheirodon spp. (Characiformes: Characidae: Stethaprioninae), including comments on Petitella georgiae and a Hemigrammus bleheri
}

Pedro Senna Bittencourt pedro_bittencourt@yahoo.com.br

Submitted September 9, 2019

Accepted May 4, 2020

by Guilherme Orti

Epub Jun 26, 2020
${ }^{\oplus}$ Pedro Senna Bittencourt ${ }^{1},{ }^{\oplus}$ Valéria Nogueira Machado ${ }^{1}$, ${ }^{\oplus}$ Bruce Gavin Marshall ${ }^{2}$, ${ }^{\circ}$ Tomas Hrbek ${ }^{1}$ and ${ }^{\oplus}$ Izeni Pires Farias ${ }^{1}$
Neon tetras (Paracheirodon spp.) are three colorful characid species with a complicated taxonomic history, and relationships among the species are poorly known. Molecular data resolved the relationships among the three neon tetras, and strongly supported monophyly of the genus and its sister taxon relationship to Brittanichthys. Additionally, the sister-taxon relationship of the rummy-nose tetras Hemigrammus bleheri and Petitella georgiae was strongly supported by molecular and morphological data. Therefore, we propose to transfer the rummy-nose tetras H. bleheri and H. rhodostomus to the genus Petitella. Furthermore, Petitella georgiae is likely to be a species complex comprised of at least two species.

Keywords: Blood-red tetras, Characids, Neon tetras, Phylogeny, Rummy-nose tetras.
Online version ISSN 1982-0224

Print version ISSN 1679-6225

Neotrop. Ichthyol.

vol. 18, no. 2, Maringá 2020
1 Laboratório de Evolução e Genética Animal (LEGAL), Departamento de Genética, Universidade Federal do Amazonas (UFAM), Av. Gen. Rodrigo Octávio Jordão Ramos, 3000, Coroado, 69080-900 Manaus, AM, Brazil. (PSB) pedro_bittencourt@yahoo.com.br, (corresponding author); (VNM) valeria.pesca@gmail.com; (TH) hrbek@evoamazon.net; (IPF) izeni@evoamazon.net.

2 Norman B. Keevil Institute of Mining Engineering, University of British Columbia, 517-6350 Stores Road, Vancouver, B.C. V6T 1Z4, Canada. brucegmarshall@gmail.com. 
Os neon tetras (Paracheirodon spp.) são três espécies de caracídeos coloridos com uma complicada história taxonômica e as relações entre suas espécies são pouco conhecidas. Dados moleculares resolveram as relações entre os três neons tetras, suportando fortemente a monofilia do gênero e a relação de grupo-irmão com Brittanichthys. Adicionalmente, a relação de grupo-irmão entre os rodóstomos Hemigrammus bleheri e Petitella georgiae foi fortemente suportada por dados moleculares e morfológicos. Portanto, nós propomos transferir os rodóstomos $H$. bleheri e H. rhodostomus para o gênero Petitella. Além disso, é possível que Petitella georgiae seja um complexo de espécies composto por, pelo menos, duas espécies.

Palavras-chave: Caracídeos, Filogenia, Rodóstomo, Tetras neon, Tetras sanguevermelho.

\section{INTRODUCTION}

Among characiforms, Characidae is the most diverse Neotropical fish family, with 1,188 valid species, of which 206 were described in the last ten years (Fricke et al., 2020a). Most members of Characidae are small-sized fishes, under $<8 \mathrm{~cm}$ standard length (SL), and many are popular aquarium species commonly known as "tetras" (Mirande, 2019).

The genus Paracheirodon Géry, 1960 is comprised of three small, brilliantly colored neon tetra species from South America (Weitzman, Fink, 1983) which are popular in the aquarium trade. Paracheirodon axelrodi (Schultz, 1956) and P. simulans (Géry, 1960) occur in small streams and headwater tributaries of the Negro and Orinoco rivers (Weitzman, Fink, 1983; Marshall et al., 2011), while P. innesi (Myers, 1936) occurs in blackwater and clearwater streams of the Ucayali-Solimões and Purus rivers (Weitzman, Fink, 1983). Paracheirodon, thus, is an emblematic example of a group of Amazonian fishes that are distributed in a biogeographical region known as the "Central Blackwater Amazon" (Dagosta, de Pinna, 2019).

Historically, both P. innesi and P. simulans were described as species of the genus Hyphessobrycon Durbin, 1908 (Myers, 1936; Géry, 1960), while P. axelrodi was originally described as a species of the genus Cheirodon Girard, 1855 (Schultz, 1956). Géry (1960) established the genus Paracheirodon - designating H. innesi as its type species - due to its morphological affinities with Cheirodon axelrodi, but differing from it by the presence of tricuspid uniserial premaxillary teeth. Consequently, until Weitzman, Fink (1983) performed a taxonomic review of the neon tetras, whereby all of the species were placed within the genus Paracheirodon, these three species were in three distinct genera (Cheirodon, Paracheirodon, and Hyphessobrycon) in two different characid subfamilies (Tetragonopterinae and Cheirodontinae).

The taxonomic review of Weitzman, Fink (1983) provided eight morphological synapomorphies to support the monophyly of Paracheirodon. However, relationships among the three species were not well established and the authors did not provide any hypothesis of phylogenetic relationships between Paracheirodon and other characid groups, due to a lack of phylogenetic informativeness of the morphological 
data available at the time. They also provided one synapomorphy for the clade $P$. axelrodi and P. innesi, namely the dorsal placement of the lateral blue body stripe and its posterior termination near the base of the adipose fin, which in $P$. simulans reaches the caudal fin base.

Multilocus (Javonillo et al., 2010; Oliveira et al., 2011), mitogenome (Yan et al., 2017), and total-evidence (Mirande, 2019) phylogenies support the inclusion of Paracheirodon in the subfamily Stethaprioninae (also called "Clade C" or "Clade 52" in Javonillo et al. (2010) and Oliveira et al. (2011), respectively), as well as the sister-species relationship of P. axelrodi and P. innesi; however, none of these studies included P. simulans. These phylogenies also provided new sister-group relationships with species of other genera such as Brittanichthys axelrodi Géry, 1965, Hemigrammus bleheri Géry, Mahnert, 1986, some species of Hyphessobrycon (H. santae Eigenmann, 1907, H. compressus Meek, 1904, H. pulchripinnis Ahl, 1937, H. eques Steindachner, 1882, H. megalopterus Eigenmann, 1915, H. erythrostigma Fowler, 1943, and H. socolofi Weitzmann, 1977), which Mirande (2019) refers it as the "true" Hyphessobrycon, and Petitella georgiae Géry, Boutière, 1964. However, as there are no morphological or molecular phylogenetic studies including P. simulans, the monophyly of Paracheirodon has never been tested using molecular data. Consequently, the phylogenetic relationships among the three species of the genus have yet to be resolved. Therefore, the aim of the current study was to test the Paracheirodon monophyly hypothesis using a molecular phylogenetic approach, through analysis of the mitochondrial genes cytochrome $\mathrm{C}$ oxidase subunit I (COI) and the $16 \mathrm{~S}$ ribosomal RNA (16S rRNA).

\section{MATERIAL AND METHODS}

Study area and sample collection. Sampling of $P$. simulans was carried out in palm swamps in an interfluvial region of the middle Negro River, at the headwaters of Igarapé Tulia $\left(0^{\circ} 40^{\prime} 0.12^{\prime} \mathrm{S}, 63^{\circ} 33^{\prime} 51.48\right.$ ”W), during 2009-2010 (see Marshall et al., 2011 for a complete field description). We also sequenced five Brittanichthys axelrodi specimens from Santa Isabel do Rio Negro ( $0^{\circ} 36^{\prime} 58^{\prime}$ ' S, 6455’24” W), due to its close phylogenetic relationship with the genus Paracheirodon (Javonillo et al., 2010; Mirande, 2019), as well as one individual of Petitella georgiae from the Purus River (6²2’30" S, 6316'29”W), since Mirande (2019) suggests a close phylogenetic relationship of Petitella and Paracheirodon. Individuals were collected using small dip nets, then preserved in 95\% ethanol while in the field, before being deposited posteriorly in the Universidade Federal do Amazonas animal tissue collection (CTGA) using individual ID tags (Tab. 1).

Molecular data. Whole genomic DNA from the muscle tissue of five $P$. simulans individuals was extracted using 2\% CTAB solution (2\% CTAB, $1.4 \mathrm{M}$ $\mathrm{NaCl}, 20 \mathrm{mM}$ EDTA, $100 \mathrm{mM}$ Tris HCl, 1\% PVP) (Doyle, Doyle, 1987), plus 15 $\mathrm{mg} / \mathrm{mL}$ of Proteinase K. The mitochondrial gene cytochrome $\mathrm{C}$ oxidase subunit I (COI) was PCR-amplified using the M13-tailed cocktails FishF2/FishR2 and VF2/VR1d (Ivanova et al., 2007), and 16S rRNA using primers 16S-L2508 (5'-CTCGGCAAACATAAGCCTCGCCTGTTTACCAAAAA-3') and 16SH-SLA 
TABLE 1 I Specimens analyzed in this study. Species listed are valid names. Collection abbreviations are as follows: CTGA, Coleção de Tecidos de Genética Animal, Universidade Federal do Amazonas, Manaus, Brazil.

\begin{tabular}{|c|c|c|c|}
\hline \multirow{2}{*}{ Species } & \multirow{2}{*}{ Specimen } & \multicolumn{2}{|c|}{ GenBank accession number } \\
\cline { 3 - 4 } & & 16S rRNA & COI \\
\hline Brittanichthys axelrodi & CTGA 105358 & MN971616 & MN974145 \\
\hline Brittanichthys axelrodi & CTGA 105360 & MN971617 & MN974146 \\
\hline Brittanichthys axelrodi & CTGA 105362 & MN971618 & MN974147 \\
\hline Brittanichthys axelrodi & CTGA 105594 & MN971619 & MN974148 \\
\hline Brittanichthys axelrodi & CTGA 105595 & MN971620 & MN974149 \\
\hline Paracheirodon simulans & CTGA 17659_1 & MN971621 & MN974150 \\
\hline Paracheirodon simulans & CTGA 17659_2 & MN971622 & MN974151 \\
\hline Paracheirodon simulans & CTGA 17659_3 & MN971623 & MN974152 \\
\hline Paracheirodon simulans & CTGA 17659_4 & - & MN974153 \\
\hline Paracheirodon simulans & CTGA 17659_5 & MN971624 & MN974154 \\
\hline Petitella georgiae & CTGA 103222 & MN971625 & MN974155 \\
\hline
\end{tabular}

(5'-TGCACCATTRGGATGTCCTGATCCAA-3') in a total of $15 \mu \mathrm{L}$ PCR mix, which included $1.5 \mu \mathrm{L} 25 \mathrm{mM} \mathrm{MgCl}_{2}, 1.5 \mu \mathrm{L} 10 \mathrm{mM}$ dNTPs (2.5 mM each dNTP), 0.5 $\mu \mathrm{L} 20 \mathrm{mg} / \mu \mathrm{L}$ Bovine Serum Albumin (BSA), $1.5 \mu \mathrm{L}$ 10X Taq Buffer plus KCl (100 mM Tris- $\mathrm{HCl}-\mathrm{pH} 8.8$ at $25^{\circ} \mathrm{C}-500 \mathrm{mM} \mathrm{KCl}, 0.8 \%(\mathrm{v} / \mathrm{v})$ Nonidet $\left.\mathrm{P} 40\right), 1.5 \mu \mathrm{L}$ of primer cocktails ( 2 pM each), $0.5 \mu \mathrm{L} \mathrm{Taq} \mathrm{DNA} \mathrm{polymerase}(1 \mathrm{U} / \mu \mathrm{L}), 1.0 \mu \mathrm{L}$ of template DNA (50 to $100 \mathrm{ng} / \mu \mathrm{L}$ ), and $7.0 \mu \mathrm{L}$ of $\mathrm{ddH}_{2} 0$. PCR cycling conditions were as follows: $94^{\circ} \mathrm{C}$ (30 s), 35 cycles of $94^{\circ} \mathrm{C}(30 \mathrm{~s}), 50^{\circ} \mathrm{C}(35 \mathrm{~s}$ for COI; $40 \mathrm{~s}$ for $16 \mathrm{~S} \mathrm{rRNA})$, and $72^{\circ} \mathrm{C}(90$ s) followed by $72^{\circ} \mathrm{C}(5 \mathrm{~min})$. Exonuclease I - Shrimp Alkaline Phosphatase (ExoSAP) was used to purify PCR products that were then used for fluorescent dye terminator sequencing, applying the same PCR primers following the manufacturer's protocols for ABI BigDye Terminator (ThermoFisher). The sequencing reaction products were precipitated using a 100\% ethanol/125 mM EDTA solution, which was then resuspended in Hi-Di Formamide, and resolved on ABI 3500XL automatic sequencer (ThermoFisher).

Molecular data of $P$. axelrodi, $P$. innesi, and other characids obtained from GenBank were also included for posterior data analysis (Tab. S1). All sequences generated in this study have been deposited in GenBank (Tab. 1).

Data analysis. The nucleotide sequences were organized and verified using Geneious 6 (Kearse et al., 2012). The forward and reverse chromatogram reads for each sequenced sample were assembled into contigs and verified visually. The COI nucleotide sequences were also translated into putative amino acids; no internal stop codons were found. Additional COI and $16 \mathrm{~S}$ rRNA data of P. axelrodi, P. innesi and other characids from the "clade C" of Javonillo et al. (2010) were also included. We also conducted a detailed search in GenBank for additional data of Stethaprioninae sensu Mirande (2019) submitted posteriorly to the publications of Javonillo et al. (2010) and Oliveira et al. (2011). All sequences obtained from GenBank were checked for species misidentification and the taxonomic status of all terminal taxa were evaluated using 
Eschmeyer's Catalog of Fishes (Fricke et al., 2020b). We used MAFFT v7.07 (Katoh et al., 2002) to perform an automatic alignment of COI and 16S rRNA sequences separately, followed by a final visual verification. After alignment, COI and 16S rRNA sequences of each species were concatenated prior to performing a Maximum Likelihood (ML) phylogenetic inference using RAxML 8.1.21 (Stamatakis, 2014). Tree searches were made under the GTRGAMMA substitution model, and the extended majority-rule consensus tree criterion (autoMRE) was used to determine the number of sufficient bootstrap replicates. No partitioning schemes were applied.

\section{RESULTS}

A maximum sequence length of $642 \mathrm{bp}$ of the cytochrome C oxidase subunit I and 556 bp of the $16 \mathrm{~S}$ ribosomal RNA was obtained after the alignment and manual edition of five P. simulans samples. For Brittanichthys axelrodi, a maximum of $669 \mathrm{bp}$ of the COI and $566 \mathrm{bp}$ of the $16 \mathrm{~S}$ rRNA was recovered, while Petitella georgiae had $536 \mathrm{bp}$ of the $\mathrm{COI}$ and $590 \mathrm{bp}$ of the $16 \mathrm{~S}$ rRNA recovered. The alignment, including other characids, had sequence lengths between 516 and 581 bp for $16 \mathrm{~S}$ rRNA and 522 to 678 bp for COI, while the concatenated dataset had a total of $1318 \mathrm{bp}$. Uncorrected p-distance between $P$. simulans and $P$. axelrodi, and $P$. simulans and $P$. innesi COI sequences were $16.6 \%$ and $16.2 \%$, respectively, while p-distance between $P$. axelrodi and $P$. innesi was $10.0 \%$ (Tab. 2).

The phylogenetic reconstruction using the COI and $16 \mathrm{~S}$ rRNA concatenated dataset recovered the monophyly of Paracheirodon with high bootstrap support (91\%), where $P$. axelrodi and $P$. innesi figure as sister species, while $P$. simulans is sister to this clade (Fig. 1). The results also support Brittanichthys as the sister-group of Paracheirodon (98\% bootstrap support). Petitella georgiae from Peru and the Purus River were sister taxa, albeit divergent $(\mathrm{p}$-distance $=9.1 \%)$, and formed sister clade to Petitella bleheri $(\mathrm{p}$-distance $=12.6 \%)$; this phylogenetic relationship was highly supported $(100 \%$ bootstrap support). In contrast, we were unable to confirm the monophyly of the clade comprised of Paracheirodon, Brittanichthys, Petitella georgiae + Petitella bleheri, as proposed by Mirande (2019).

TABLE 2 I Uncorrected pairwise p-distance between species of Paracheirodon, Brittanichthys axelrodi. Petitella georgiae and Petitella bleheri. Distances were calculated using a $678 \mathrm{bp}$ fragment of the citochrome $\mathrm{C}$ oxidase subunit I gene.

\begin{tabular}{|l|c|c|c|c|c|c|c|}
\hline \multicolumn{1}{|c|}{ Species } & $\mathbf{1}$ & $\mathbf{2}$ & $\mathbf{3}$ & $\mathbf{4}$ & $\mathbf{5}$ & $\mathbf{6}$ & $\mathbf{7}$ \\
\hline 1. Paracheirodon axelrodi & - & & & & & \\
\hline 2. Paracheirodon innesi & 0.100 & - & & & & \\
\hline 3. Paracheirodon simulans & 0.166 & 0.162 & - & & & \\
\hline 4. Brittanichthys axelrodi & 0.169 & 0.167 & 0.174 & - & & \\
\hline 5. Petitella georgiae Purus & 0.183 & 0.195 & 0.201 & 0.151 & - & \\
\hline 6. Petitella georgiae Peru & 0.196 & 0.193 & 0.200 & 0.156 & 0.091 & - & \\
\hline 7. Petitella bleheri & 0.184 & 0.184 & 0.196 & 0.180 & 0.126 & 0.126 & - \\
\hline
\end{tabular}


FIGURE 1 I Maximum

Likelihood phylogenetic reconstruction of Stethaprioninae sensu Mirande (2018) using 16S ribosomal RNA and cytochrome $\mathrm{C}$ oxidase subunit I concatenated dataset after inclusion of Paracheirodon simulans and Petitella georgiae. Bootstrap values $(\geq 75 \%)$ are shown near the nodes. Neon tetras are highlighted in red, and rummy-nose tetras are highlighted in blue.

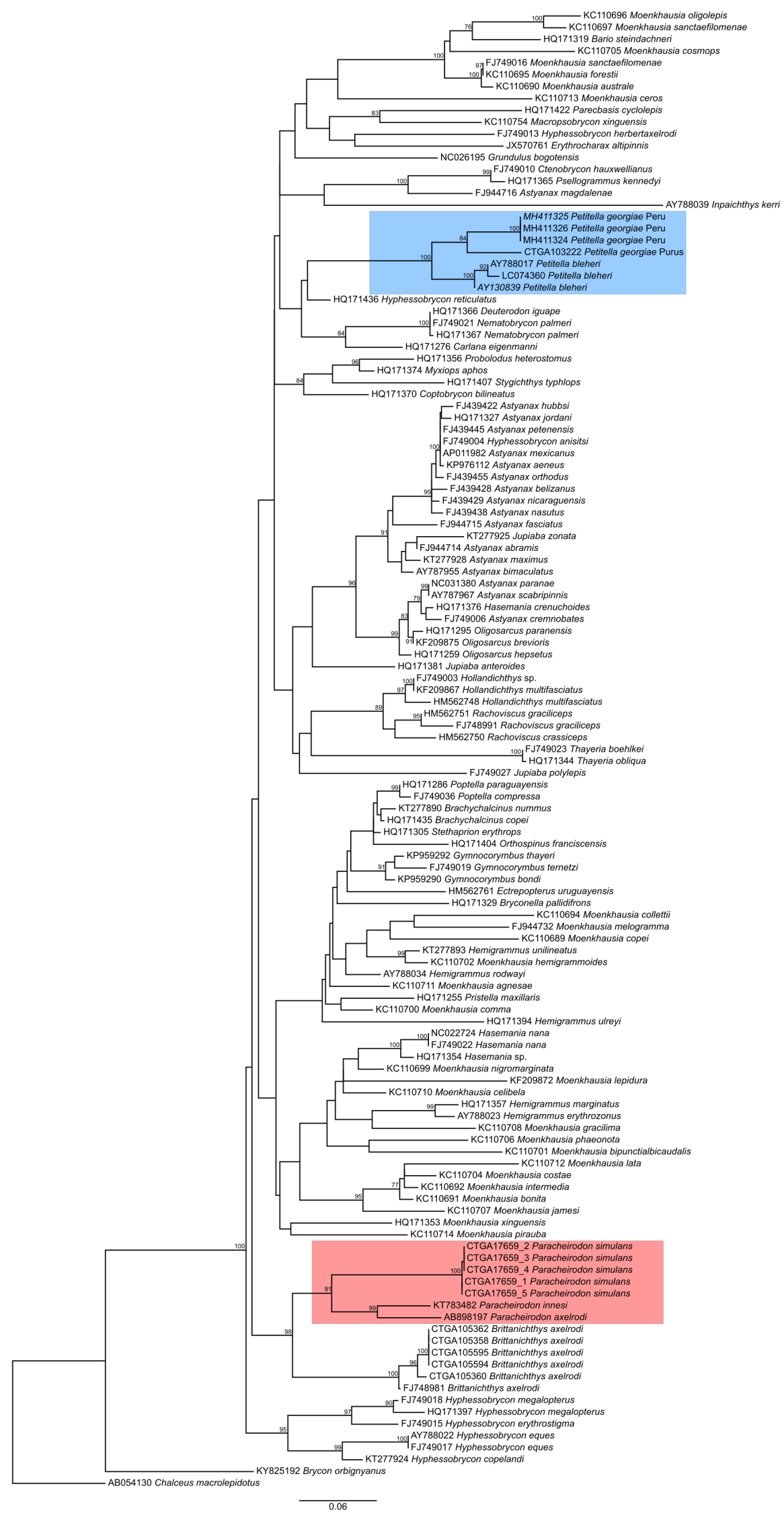




\section{Petitella Géry \& Boutière, 1964}

Type-species. Petitella georgiae Géry \& Boutière, 1964

Diagnosis. The genus Petitella is readily distinguished from all remaining characid genera by the possession of a distinctively bright red head, the presence of a black horizontal bar that extends from the end of the caudal peduncle to the middle rays of the caudal-fin, and the presence of an oblique black bar in each caudal-fin lobe, separated by white colored bands. Contact between frontals anterior to frontal fontanel present; posterodorsal margin of ethmoid cartilage and lateral ethmoids distant from lateral ethmoids; 17 or fewer branched anal-fin rays; only one or two anal-fin hooks on each ray of adult males; the presence of parallel longitudinal ridges on the posterior field of scales; scales covering one-third of the length of caudal-fin lobes; coloration of the head distinctively red, especially the snout.

Petitella bleheri (Géry \& Mahnert, 1986), new combination

Hemigrammus bleheri Géry \& Mahnert, 1986:41, fig. unnumb. (original description; type-locality: Middle Rio Negro basin, Brazil, probably near Rio Jufaris).

Petitella rhodostoma (Ahl, 1924), new combination

Hemigrammus rhodostomus Ahl, 1924:405, fig. unnumb. (original description; typelocality: Pará). - Ramsperger, 1924:810 (type-locality description: tributary of the Rio Tapajoz [Tapajós], Santarém, Pará).

Comparative remarks. Petitella georgiae is distinguished from its congeners by a long and wide maxillary ( $v$ s. very short and round in P. bleheri, and short in P. rhodostoma); single row of premaxillary teeth ( $v$ s. two in P. bleheri and P. rhodostoma); dentary with 9-11 teeth with 5 cuspids (vs. 6, with 6 or 7 cuspids, followed by 1 or 2 tricuspidate ones in P. bleheri, and 5-6 with 5 cuspids, usually followed by 4 conical teeth in $P$. rhodostoma); absence of black spot on lower posterior border of caudal peduncle ( $v s$. present in P. bleheri and P. rhodostoma).

Petitella bleheri is distinguished from its congeners by the much more intense and widespread red color of the head, extending up to the humeral region ( $v$ s. limited red coloration and not extending to humeral region in $P$. georgiae and P. rhodostoma); horizontal black bar on the end of the caudal peduncle is never prolonged forward ( $v s$. prolonged up to the anal-fin in P. georgiae and P. rhodostoma); anal-fin hyaline ( $v$ s. a black bar on the base of the anterior part of the anal-fin, continuing obliquely on the branched rays in P. georgiae and P. rhodostoma).

Petitella rhodostoma is distinguished from its congeners by the red head color not extending to the humeral region and the presence of a black spot on the lower posterior border of the caudal peduncle ( $v$ s. head color not extending to humeral region with only one black spot on caudal peduncle in $P$. georgiae, and head color extending to humeral with two black spots on caudal peduncle in P. bleheri); dentary with 5-6 teeth, with 5 cuspids, usually followed by 4 conical ones ( $v$ s. 9-11 teeth, with 5 cuspids in P. georgiae, and 6 teeth, with 6 or 7 cuspids, followed by 1 or 2 tricuspidate ones in P. bleheri). 


\section{DISCUSSION}

Our results support the monophyly of Paracheirodon, proposed by Weitzman, Fink (1983) based on morphological data. In addition, the sister-species relationship of P. axelrodi and $P$. innesi was also confirmed, which had been suggested by the same authors based on the position and termination of the blue lateral body stripe in the vicinity of the adipose fin.

Numerous analyses published in the last two decades have helped to clarify phylogenetic relationships within Characiformes, including characids (e.g. Orti et al., 2008, Javonillo et al., 2010; Oliveira et al., 2011, Thompson et al., 2014, Mirande, 2019). The two large-scale phylogenies of Characiformes (Javonillo et al., 2010; Oliveira et al., 2011) subdivided the Characidae into three principal clades, with Javonillo et al. (2010) being the first to reveal the monophyly of Paracheirodon, Brittanichthys, Petitella bleheri and the "true" sensu Mirande (2019) species of Hyphessobrycon. Using a total-evidence phylogenetic approach, Mirande (2019) found the same clade composition and the same phylogenetic relationships: ((Paracheirodon, Brittanichthys), the "Petitella clade" [P. bleheri + P. georgiae]), the "true" Hyphessobrycon).

Following Mirande (2019), all of these genera and species share only one morphological synapomorphy: the pelvic-fin bony hooks absent in adult males of species bearing hooks on fins (see Appendix S8, node 988). However, in this study, we were unable to recover phylogenetic relationships other than the sister taxon relationship of Paracheirodon and Brittanichthys, due to a lack of phylogenetic information in the COI and 16S rRNA genes for deep phylogenetic nodes (Javonillo et al., 2010).

The phylogenetic reconstruction (Fig. 1) also confirms Petitella georgiae as a sistergroup of Petitella bleheri. The striking p-distance divergence (9.1\%) between the Peruvian P. georgiae and our samples from the Purus River indicates the possibility of Petitella georgiae being a species complex. The monophyly of P. bleheri and P. georgiae was highly supported in our analyses - the first time Petitella georgiae was included in any molecular phylogeny - as well as by the morphological data of Mirande (2019), who reported seven morphological synapomorphies supporting the sister-taxon relationship between these two species (see Appendix S8, node 1129).

Petitella georgiae, Petitella bleheri and Petitella rhodostoma (Ahl, 1924) share a very similar coloration marked by an intensely bright red head and the presence of three conspicuous horizontal black bars on the caudal fin (Mirande, 2010). Although Géry, Mahnert (1986) compared the type material of H. bleheri to both H. rhodostomus and $P$. georgiae, they chose not to discuss either phylogenetic affinities or the validity of the genus Petitella itself, due to the "new weights being given to certain cranial characters in the tetras as proposed by certain anatomists", citing Weitzman, Fink (1983). Mirande (2010) stated that "Petitella georgiae Géry \& Boutière is mainly distinguished from Hemigrammus bleheri by having only one row of premaxillary teeth ( $v s$. two rows)".

Although P. rhodostoma was not included in our analyses nor in Mirande's (2019) matrices, there is little doubt that these three species are very closely related and likely form a monophyletic group. Only the rummy-nose tetras share a distinctive and intensely bright red head, which is of different color and pattern than the rest of the body - a pattern not observed in any other characid species (Mirande, 2019, Appendix S1, character 491). Given that both morphological and molecular data support monophyly of these species, and Hemigrammus Gill, 1858 has been demonstrated as 
a non-monophyletic entity in multiple studies (Javonillo et al., 2010; Oliveira et al., 2011; Mirande, 2009, 2010, 2019) and in our study Hemigrammus unilineatus Gill, 1858, the type species of Hemigrammus, is sister to Moenkhausia hemigrammoides Géry, 1965, we therefore suggested the transfer of both H. bleheri and H. rhodostomus to the genus Petitella Géry \& Boutière, 1964 and provided a tentative diagnosis for the genus based on original descriptions of the species and the morphological synapomorphies of Mirande (2019). Compelling evidence for the monophyly of the rummy-nose tetras has been published in the recent years using morphological (Lima, Souza, 2009; Mirande, 2010), molecular (this study) and total-evidence (Mirande, 2019) datasets.

By the inclusion of new taxa into characid phylogenies, it was possible to confirm previous hypotheses and propose new ones. However, it is also important to point out that there is still a huge knowledge gap regarding phylogenetic relationships of Characidae, which is likely to remain for some time. For example, of the 141 genera recognized by Mirande (2019), at least 40 do not have any molecular data available in GenBank (pers. obs.) and many genera and species remain incertae sedis. This is due to a lack of information beyond their original descriptions, which makes it difficult to infer phylogenetic relationships of these species and genera, which, in turn, guide higher-order classification.

\section{ACKNOWLEDGMENTS}

This work was supported by research funding through Conselho Nacional de Desenvolvimento Científico e Tecnológico (CNPq) and Fundação de Amparo à Pesquisa do Estado do Amazonas (FAPEAM) (grants CNPq/FAPEAM/SISBIOTA, Rede BioPHAM 563348/2010 to IPF). The authors are also grateful to Lúcia Rapp Py-Daniel and the ichthyology team of SISBIOTA for collection and identification of Brittanichthys axelrodi and Petitella georgiae. In addition, special thanks to Aline Ximenes and Mayara Silva for assistance in the laboratory, the anonymous reviewers for their comments and suggestions, and Igor Roberto for comments on the manuscript.

\section{REFERENCES}

- Ahl, E. Ueber eine farbenprächtige Neuheit, Hemigrammus rhodostomus E. Ahl. sp. n. Wochenschr Aquarien Terr. 1924; 21(18): 405. Available from: http:// dlibra.bibliotekaelblaska.pl/dlibra/ docmetadata?id=50656

- Dagosta FCP, de Pinna MCC. The fishes of the Amazon: Distribution and biogeographical patterns with a comprehensive list of species. Bull Am Mus Nat Hist. 2019; 431. Available from: http:/ digitallibrary.amnh.org/handle/2246/6940

- Doyle JJ, Doyle JL. A rapid DNA isolation procedure for small quantities of fresh leaf tissue. Phytochem Bull. 1987; 19(1):11-15.
- Fricke R, Eschmeyer WN, Fong JD. Eschmeyer's catalog of fishes: Species by family/subfamily [Internet]. San Francisco: California Academy of Science; 2020a. Available from: http://researcharchive. calacademy.org/research/ichthyology/ catalog/SpeciesByFamily.asp

- Fricke R, Eschmeyer WN, Van der Lann R. Eschmeyer's catalog of fishes: genera, species, references [Internet]. San Francisco: California Academy of Science; 2020b. Available from: http:// researcharchive.calacademy.org/research/ ichthyology/catalog/fishcatmain.asp 
- Géry J. Contributions to the study of characoid fishes. 11. The generic position of Hyphessobrycon innesi and Cheirodon axelrodi, with a review of the morphological affinities of some Cheirodontinae (Pisces - Cypriniformes). Bull Aquat Biol. 1960; 2(12):1-18.

- Géry J, Mahnert V. A new rummynose tetra from the Rio Negro, Brazil: Hemigrammus bleheri n. sp. (Characidae, Tetragonopterinae), with comments on Paracheirodon. Trop Fish Hobbyist. 1986; 34(11):37-52.

- Ivanova NV, Zemlak TS, Hanner RH, Hebert PDN. Universal primer cocktails for fish DNA barcoding. Mol Ecol Notes. 2007; 7(4):544-48. https://doi.org/10.1111/ j.1471-8286.2007.01748.x

- Javonillo R, Malabarba LR, Weitzman SH, Burns JR. Relationships among major lineages of characid fishes (Teleostei: Ostariophysi: Characiformes), based on molecular sequence data. Mol Phylogenet Evol. 2010 ; 54(2):498-511. https://doi. org/10.1016/j.ympev.2009.08.026

- Katoh K, Misawa K, Kuma K, Miyata T. MAFFT: a novel method for rapid multiple sequence aligment based on fast Fourier transform. Nucleic Acids Res. 2002; 30(14):3059-66. https://doi.org/10.1093/nar/ gkf436

- Kearse M, Moir R, Wilson A, Stones-Havas $\mathrm{S}$, Cheung M, Sturrock S et al. Geneious Basic: An integrated and extendable desktop software platform for the organization and analysis of sequence data. Bioinformatics. 2012; 28(12):1647-49. https://doi.org/10.1093/ bioinformatics/bts199

- Lima FCT, Souza LM. A new species of Hemigrammus from the upper rio Negro basin, Brazil, with comments on the presence and arrangement of anal-fin hooks in Hemigrammus and related genera (Ostariophysi: Characiformes: Characidae). Aqua: Int J Ichthyol. 2009; 15(3):153-68.

- Marshall BG, Forsberg BR, Hess LL, Freitas CEC. Water temperature differences in interfluvial palm swamp habitats of Paracheirodon axelrodi and $P$. simulans (Osteichthyes: Characidae) in the middle Rio Negro, Brazil. Ichthyol Explor Freshwaters. 2011; 22(4):377-83.

- Mirande JM. Weighted parsimony phylogeny of the family Characidae (Teleostei: Characiformes). Cladistics. 2009; 25(6):574-613. https://doi.org/10.1111/ j.1096-0031.2009.00262.x
- Mirande JM. Phylogeny of the family Characidae (Teleostei: Characiformes): from characters to taxonomy. Neotrop Ichthyol. 2010; 8(3):385-568. http://dx.doi. org/10.1590/S1679-62252010000300001

- Mirande JM. Morphology, molecules and the phylogeny of Characidae. Cladistics. 2019; 35(3):282-300. https://doi.org/10.1111/ cla. 12345

- Myers GS. A new characid fish of the genus Hyphessobrycon from the Peruvian Amazon. Proc Biol Soc Washington [Internet]. 1936; 49:97-98. https://www. biodiversitylibrary.org/part/43746

- Oliveira C, Avelino GS, Abe KT, Mariguela TC, Benine RC, Ortí G et al. Phylogenetic relationships within the speciose family Characidae (Teleostei: Ostariophysi: Characiformes) based on multilocus analysis and extensive ingroup sampling. BMC Evol Biol. 2011; 11(1):275. https://doi.org/10.1186/1471-2148-11-275

- Ortí G, Sivasundar A, Dietz K, Jégu M. Phylogeny of the Serrasalmidae (Characiformes) based on mitochondrial DNA sequences. Genet Mol Biol. 2008; 31(1):343-51. http://doi.org/10.1590/S141547572008000200030

- Schultz LP. The amazing new fish called the scarlet characin. Trop Fish Hobbyist. 1956; 4(4):41-43.

- Stamatakis A. RAxML version 8: a tool for phylogenetic analysis and post-analysis of large phylogenies. Bioinformatics. 2014; 30(9):1312-13. https://doi.org/10.1093/ bioinformatics/btu033

- Thompson AW, Betancur-R. R, LópezFernández H, Ortí G. A time-calibrated, multi-locus phylogeny of piranhas and pacus (Characiformes: Serrasalmidae) and a comparison of species tree methods. Mol Phylogenet Evol. 2014; 81:242-57. https:// doi.org/10.1016/j.ympev.2014.06.018

- Weitzman SH, Fink WL. Relationships of the neon tetras, a group of South American freshwater fishes (Teleostei, Characidae), with comments on the phylogeny of New World characiforms. Bull Museum Comp Zool Harvard Coll [Internet]. 1983; 150:339-95. Available from: https://www. biodiversitylibrary.org/part/28701

- Yan A, Liu F, Jiang H, Feng C, Tang D. The complete mitochondrial genome of Paracheirodon innesi. Mitochondrial DNA Part A. 2017; 28(3):377-78. https://doi.org/1 0.3109/19401736.2015.1126830 


\section{Neotropical Ichthyology}

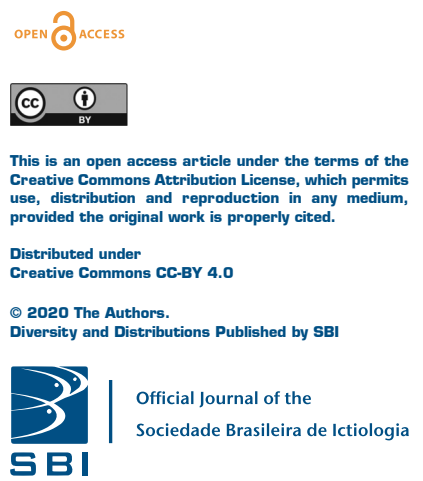

\section{AUTHOR'S CONTRIBUTION 자}

Pedro Senna Bittencourt: Conceptualization, Data curation, Formal analysis, Investigation, Methodology, Writing-original draft, Writing-review \& editing.

Valéria Nogueira Machado: Conceptualization, Data curation, Methodology, Writing-original draft,

Writing-review \& editing.

Bruce Gavin Marshall: Data curation, Funding acquisition, Methodology, Resources, Writing-review \& editing.

Tomas Hrbek: Conceptualization, Data curation, Funding acquisition, Project administration, Resources, Supervision, Validation, Writing-review \& editing.

Izeni Pires Farias: Conceptualization, Data curation, Formal analysis, Funding acquisition, Investigation, Methodology, Project administration, Resources, Supervision, Validation, Visualization, Writing-original draft, Writing-review \& editing.

\section{ETHICAL STATEMENT}

The sampling were conduced under the Instituto Brasileiro do Meio Ambiente e dos Recursos Naturais Renováveis (IBAMA) research permit \#16822.

\section{COMPETING INTERESTS}

The authors declare no competing interests.

\section{HOW TO CITE THIS ARTICLE}

- Bittencourt PS, Machado VN, Marshall BG, Hrbek T, Farias IPF. Phylogenetic relationships of the neon tetras Paracheirodon spp. (Characiformes: Characidae: Stethaprioninae), including comments on Petitella georgiae and Hemigrammus bleheri. Neotrop Ichthyol. 2020; 18(2):e190109. https://doi.org/10.1590/1982-0224-2019-0109 